\title{
Life cycle thinking in small and medium enterprises: the results of research on the implementation of life cycle tools in Polish SMEs-Part 3: LCC-related aspects
}

\author{
Jaroslaw Selech • Katarzyna Joachimiak-Lechman • \\ Zbigniew Klos • Joanna Kulczycka • \\ Przemyslaw Kurczewski
}

Received: 12 August 2013 / Accepted: 26 December 2013 /Published online: 13 March 2014

(C) The Author(s) 2014. This article is published with open access at Springerlink.com

\begin{abstract}
Purpose This article is the third of a series of articles presenting the results of research on the implementation of life cycle management tools in small- and medium-sized companies in Poland. The purpose of the three-part series of articles is to present the results of research on the implementation of life cycle tools in Polish small and medium enterprises (SMEs). This work is part of a project financed by the Polish Agency for Enterprise Development (PAED) which began in February 2011. It was carried out by the Wielkopolska Quality Institute - a business environment institution associated with the Polish Centre for LCA (PCLCA). The main practical objective of the project was to support SMEs in their business development, e.g. by expanding their horizons beyond the sphere of their operation and identifying new areas for the improvement and promotion of the products and services on offer. The specific objective of the analysis involving the assessment of life-cycle costs of products and services was an attempt to answer the question to determine whether the
\end{abstract}

\footnotetext{
Responsible editor: Gian Luca Baldo

J. Selech $(\varangle) \cdot$ K. Joachimiak-Lechman $\cdot$ Z. Klos $\cdot$ P. Kurczewski Faculty of Machines and Transport, Poznan University of

Technology, Piotrowo 3, 60-965 Poznan, Poland

e-mail: jaroslaw.selech@gmail.com

J. Selech

e-mail: jaroslaw.selech@put.poznan.pl

K. Joachimiak-Lechman

Faculty of Commodity Science, Poznan University of Economics,

Niepodleglosci 10, 61-875 Poznan, Poland

J. Kulczycka

AGH University of Science and Technology, al. Mickiewicza 30,

31-261 Cracow, Poland
}

assessment carried out in accordance with the life-cycle cost (LCC) methodology is a good tool for cost management in this type of business. Part 3 describes the results of studies on the assessment of the implementation of LCC in SMEs conducted in 50 companies involved in the project.

Methods In order to assess the effectiveness of the project and the effectiveness of the implementation of LCA and LCC, a survey was conducted of small- and medium-sized businesses where the implementation works had been fully completed. In total, 50 organisations agreed to participate in the LCC survey (while 46 in the LCA - part 2 paper), which was $71 \%$ of all the companies where the LCA and LCC studies had been carried out within the project. The survey was conducted using individual in-depth interviews. Questions to the representatives of the companies referred both to aspects of their operating in the market (characteristics of a company, its market share, management systems, environmental policy, suppliers, clients) and the implementation of their environmental service (assessment of its effectiveness, motivation, difficulties in its implementation), as well as opinions on the potential applications of LCA in their current operations.

Results and discussion The experience and observations of LCC experts resulting from their cooperation with the analysed organisations are largely supported by the results of the survey. The overall impression gained from the project is that the small- and medium-sized enterprises considered have a problem with accepting and understanding the life-cycle perspective, and show limited interest in taking liability for environmental and cost aspects beyond the mandatory legal standards and boundaries of their business operations. Nevertheless, the LCC analyses aroused much bigger interest among the companies than the environmental due to the fact that the cost aspects in companies undergoing normal development are seen as an important source of information about 
the structure of the costs generated with respect to the products or services provided. It is important to note that a very important factor encouraging businesses to join the studies was the fact that they were cost-free. Moreover, the planned introduction of a new product onto the market was the argument that often influenced the decision to implement the LCC. The survey has shown that companies rarely perform cost analyses including all stages of the life cycle of a product or service. Although the awareness of the importance of conducting economic researches for the entire life cycle of a product or service is great, it turned out to be problematic to unambiguously define the practical use of such an analysis, at least at the present stage of development of the companies surveyed. Conclusions The results obtained in the survey indicate that in the case of simple products, with a short life cycle, complex cost analyses may seem less useful. For more complex products or services, with long periods of use, high reliability required, and high operating costs, the analyses presented are useful tools that increase the economic efficiency of the projects implemented. It appears that from the point of view of polish SMEs, the usefulness of an LCA is seen mainly from the angle of opportunities for cost reduction (preferably in business) and increased sales (marketing). A good solution would be to conduct relatively simple, but integrated LCA/LCC analyses in SMEs so that the companies would clearly see the economic effects of the proposed environmental improvements.

Keywords Cost aspects $\cdot$ Implementation $\cdot$ LC perspective . SMEs

\section{Introduction}

In 2011-2013, 50 life-cycle cost (LCC) analyses were conducted as part of a project involving the implementation of LC techniques in Polish small and medium enterprises (SMEs) (Kurczewski part 1: Background and framework). The main objective of the project was to support companies in their business development, and one of the secondary objectives was to draw up cost and economic estimates of the life cycle of a product or service being studied and thus raise awareness of the cost-effectiveness of alternative investments. Since the project involved a team of members of the Polish Centre for LCA (Kulczycka et al. 2011), the reasons for its implementation went beyond purely business matters and also included methodological issues, and above all, they were intended to find out whether Polish SMEs have the potential to implement LC techniques. In addition, there was an attempt to find out whether Polish small- and medium-sized enterprises implement life-cycle thinking in terms of costs, and what measures they take in this regard. And finally, the researchers asked if there is a chance that the organisations that were analysed will return to this type of practise in the future? This seems especially important when one takes into account that the use of LC techniques by SMEs is still marginal and there are only few publications in this area (Schischke et al. 2012; TNO report 2005).

\section{Survey}

The previous publication (Witczak et al. part 2: LCA-related aspects) presented results for organisations where an environmental LCA was carried out, while the present article discusses similar results for companies where an LCC analysis was conducted. The structure of the survey questionnaire used to test the effectiveness of the implementation of the LCC analyses was analogous to the questionnaire designed for companies using the LCA. It consisted of four sections as follows: general description of an organisation, general characteristics of the analysis carried out, usefulness of its results and measures similar to life cycle costing taken by a company (Witczak et al. part 2: LCA-related aspects). Part 1 contains a more detailed description of the survey questionnaire (Kurczewski part 1: Background and framework). Special attention should be paid to the last part of the survey which, due to differences in methodological assumptions between LCA and LCC, looked at fundamentally different issues. It consisted of questions which can be divided into two groups because of differences in purpose. The first of these concerned the estimation of costs generated outside a manufacturing company, the second group of questions was designed to ascertain whether and how the organisations analysed calculate the costs of general environmental protection.

As with the assessment of the implementation of LCA, the survey was based on individual in-depth interviews (Boyce and Neale 2006) and respondents were top management representatives or those directly related to the LCC study in particular organisation.

\subsection{Survey sample}

In total, 45 enterprises out of 50 organisations in which an LCC analysis had been carried out responded to the survey. The group of organisations analysed included 32 manufacturers, 5 service providers, 2 service and production companies and 6 trading companies. Almost half of them had a workforce of 10 to 49 employees (22 companies), $31 \%$ were micro enterprises employing up to 9 people (14 companies), and 9 organisations met the criteria for medium enterprises, employing from 50 to 250 people (Table 1). Less than half of the organisations were limited liability companies (22 companies), while $25 \%$ of the enterprises were individual private businesses (self-employment). Approximately $20 \%$ of the organisations were registered partnerships, two were private 
Table 1 Characteristics of the companies participating in the survey of those where LCC was implemented - by size, legal and organisational form and management systems

1. Size of the companies analysed

\begin{tabular}{lll}
\hline Micro & 14 & $31 \%$ \\
Small & 22 & $49 \%$ \\
Medium & 9 & $20 \%$ \\
Total & 45 & $100 \%$ \\
2. Legal and organisational form of the companies analysed \\
Self employed & 11 & $24.45 \%$ \\
Private partnership & 9 & $20 \%$ \\
Registered partnership & 2 & 4.45 \\
Limited liability company & 22 & $48.88 \%$ \\
Joint-Stock company & 1 & $2.2 \%$ \\
Total & 45 & $100 \%$
\end{tabular}

3. Management systems in the companies analysed

3.1 According to the number of systems implemented

$\begin{array}{lll}\text { No systems implemented } & 35 & 56 \% \\ 1 \text { system implemented } & 8 & 28 \% \\ 2 \text { systems implemented } & 2 & 12 \% \\ 3 \text { systems implemented } & 0 & 4 \% \\ \text { Total } & 45 & 100 \%\end{array}$

3.2 According to the type of systems implemented

ISO 14001

EMAS

Cleaner production

Responsible care

ISO 9001

BHP OHSAS 18001

HACCP

ISO 22000

ISO 27001

Others

No formalised management systems

Total

$\begin{array}{ll}1 & 2.22 \% \\ 0 & 0 \% \\ 0 & 0 \% \\ 0 & 0 \% \\ 8 & 17.78 \% \\ 1 & 2.22 \% \\ 0 & 0 \% \\ 0 & 0 \% \\ 0 & 0 \% \\ 0 & 0 \% \\ 35 & 77.78 \% \\ 45 & 100 \%\end{array}$

partnerships, and one was a joint-stock company (Table 1). It is worth noting that limited liability companies with a statutory minimum capital and the obligation to maintain doubleentry bookkeeping were predominant among the enterprises responding to the survey. This suggests that such organisations have a potentially more detailed knowledge of the costs incurred, which in turn predisposes them to conduct an LCC analysis. The vast majority, namely 35 organisations, taking part in the study, had no formal management systems. Less than $20 \%$ claimed to have a quality management system according to ISO 9001, and two organisations had an occupational health and safety management system OHSAS 18001 and environmental management system according to the requirements of ISO 14001 (Table 1).
Taking into account the activities in key areas of management (environmental protection/environmental management, design/research and development, quality management, employee cost analysis and product cost analysis), it should be noted that the majority of the organisations surveyed implemented them on their own, creating an independent organisational unit for this purpose (Fig. 1). As for the three areas (design/research and development, employee cost analysis and product cost analysis), the enterprises often declared their own involvement along with outsourcing. Few organisations outsourced the tasks of the key management processes, but most often, it related to employee cost analysis (seven organisations), followed by quality management and environmental management (four organisations in each case).

As shown in Fig. 1, a certain percentage of the companies did not implement any activity in each of the areas of organisational management analysed (grey). In total, 9 out of the 45 companies surveyed claimed that they did not implement any activity relating to environmental management, while no activity was also claimed by 6 of the 45 in relation to quality management, and 5 out of the 45 in relation to product design and development. What is important from the point of view of an LCC analysis, only two respondents did not conduct any employee cost analysis and product cost analysis.

Figure 2 presents the characteristics of the supply chain of the organisations analysed. Among the dominant suppliers of the main resources and products were domestic enterprises (55\%), followed by local $(32 \%)$ and foreign companies $(10 \%)$. In the case of domestic suppliers, they were generally medium-sized enterprises, as opposed to local suppliers which were dominated by small organisations.

A similar situation applies to suppliers of auxiliary products. The group was clearly dominated by medium-sized domestic enterprises, and then small local organisations. Similarly, foreign suppliers, regardless of size, were a small percentage of stakeholders cooperating with the organisations under study. With regard to suppliers of the main and auxiliary resources and products, the companies analysed defined their position as "equal" in relation to their suppliers (in both cases, slightly over $50 \%$ ).

Almost all of the organisations that took part in the survey indicated that their clients were primarily institutional (84\%) and were usually large or medium-sized domestic organisations (Fig. 3).

2.2 LCC studies in the companies analysed - general information

Among the 45 companies surveyed, the vast majority of LCC analyses focused on products (32 analyses of this type), and only 13 of them focused on services. The two-dimensionality of the 


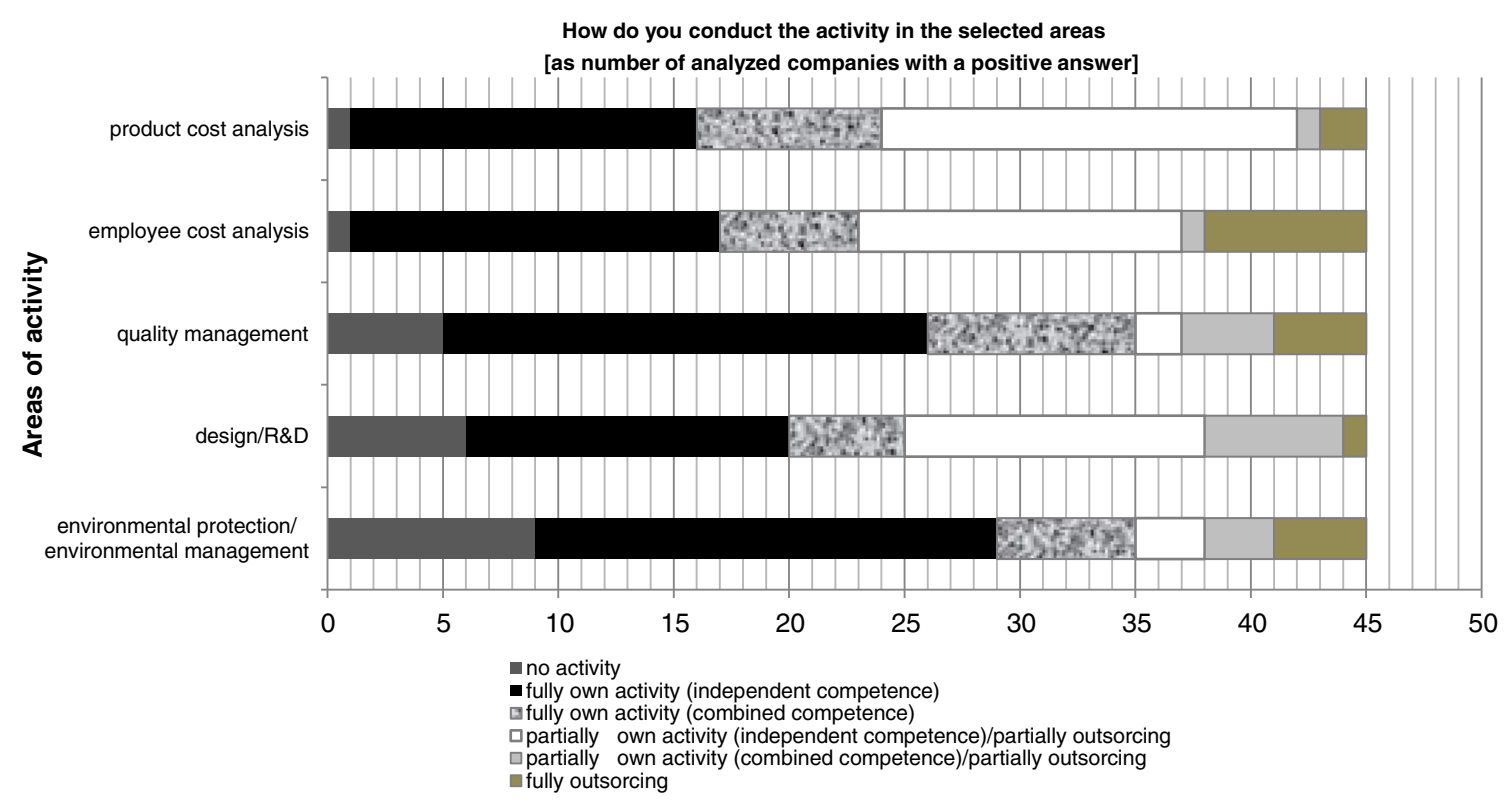

Fig. 1 Ways of conducting activity in five selected areas by the companies analysed

life cycle on which the LCC analyses focused required the use of two procedures selected by the enterprise itself. Each analysis focused on the life cycle of an investment project in the area of development, innovation and reconstruction or modernization. In appropriate cases, the procedure was supplemented by the ecological life cycle of a product, as defined in the LCA methodology. The core-product approach involved examination of the profitability of investments aimed at modernisation of the goods produced or services provided (innovative investments), investments that lead to the implementation of a project to produce completely new products or services, (development) or reconstruction and modernisation, involving the replacement of worn or obsolete assets. The second LCC option presented to the companies provided the opportunity to estimate the total cost of the physical life cycle of a product, and this extended procedure was used in ten cases.

Considering the scope of an LCC analysis, it should be noted that it is not the same as the scope of an LCA, since the latter always focuses on the stages of the environmental life cycle and hence the division is as follows: cradle-to-grave (the entire life cycle), cradle-to-gate (production stage), gateto-gate (stage of use) and gate-to-grave (end-of-life management). In the context of investment, which is the essence of an LCC analysis (Gluch and Baumann 2004; Schmidt 2003), it is appropriate to analyse the entire life cycle of an investment, no matter what stage of the environmental life cycle of a product the investment concerns. Therefore, in each case, the costs of acquisition, ownership and disposal (PN-EN 60300-3-3 2006) were calculated, while for the physical life cycle of a product, the analysis involved the costs of the main stages of a life cycle, namely: production, use and end-of-life management. This two-dimensional approach is particularly important as it allows us to answer the question: to what extent will investments in the alternative solutions increase the profitability of a company and reduce overall costs in terms of the environmental life cycle of a product.

As with an LCA, the study was initiated at an introductory meeting during which the essential purpose and scope of the analysis were discussed. On this basis, a form was developed which allowed the necessary data to be collected. Only eight
Fig. 2 Suppliers of the companies analysed - according to their size and geographical scope
Suppliers of the main resources and products

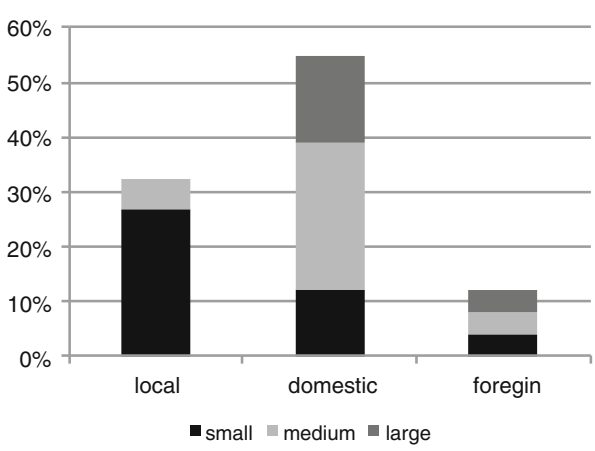

Suppliers of the auxiliary products

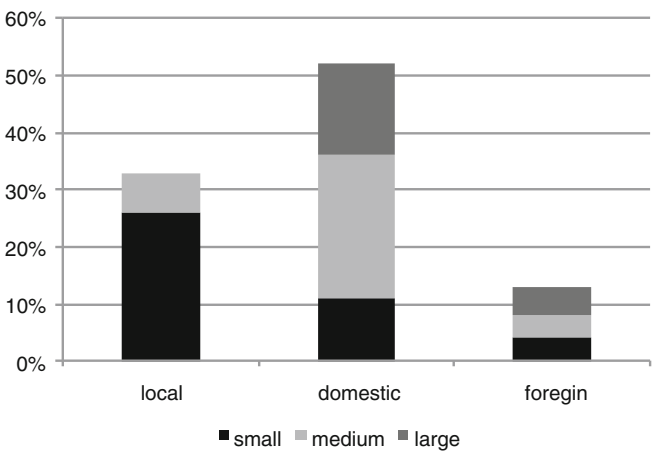


Fig. 3 Clients of the companies analysed - according to type and geographical scope

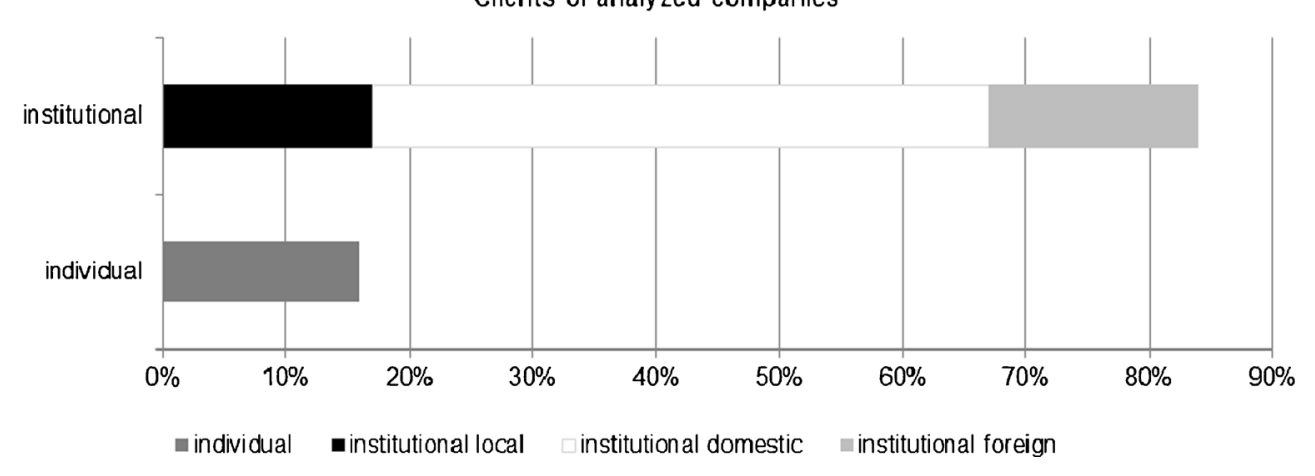

companies collected data on their own, without the help of LCC experts. More organisations, however, used the support of the researchers, either partially (17 cases) or fully (20 cases). The partial support was mainly focused on maintaining personal, mail or telephone contacts to clarify issues at stake. The full support focused on the deployment of a researcher to collect the necessary primary and secondary data.

Each time an LCC analysis ended up submitting a report on the implementation of the study. The report presented the methodical outline of the LCC, research assumptions, categories and cost structure, calculation of the LCC as well as recommendations and conclusions. The information contained in the reports was considered understandable, though moderately easy.

In nearly all cases, the decisions to undertake LCC studies were made by top management, and only in three organisations was the decision taken by professionals responsible for this area of management. In the vast majority of the organisations (more than $80 \%$ ), the conduct of the study was directly supervised by representatives of top management, by chief specialists in six organisations and by accountants in only in two of them.

The analysis of the reasons given by the enterprises for implementing the LCC techniques (Table 2) led to the conclusion that the most important factor for them was that the services being carried out were provided free of charge - the weighted average for this reason is 4.24 , while given the opportunity to show a certificate confirming participation in the project and cooperation with a centre supporting entrepreneurship which is well-known in the region produced a result of approximately 4 . A relatively high weighted average was also recorded for product improvement plans-about 3.72 . The smallest impact on the decision to carry out an LCC was assigned to the preferences of stakeholders: suppliers and clients (respectively, 1.72 and 1.9) (Table 2).

\section{Usefulness of LCC for the companies analysed}

The third part of the survey was to verify whether the LCC analyses were useful for entrepreneurs. The results were found to be useful by $43 \%$ of respondents, very significant by $18 \%$, while $9 \%$ of respondents considered the analyses to be completely unnecessary and did not have a specific view (Fig. 4). The weighted average for the entire group was 3.48 on a 0 to 5 scale. This means that the majority of respondents believe that the LCC analyses are moderately useful.

A further part of the questionnaire concerned the areas of activity in which the results of the LCC studies could be used. Entrepreneurs would more eagerly use the study results in product development as the weighted average for this category was 3.20 on a 0 to 5 scale. Following this, the respondents chose shaping the image of a product (2.66), shaping the image of a company (2.59) and marketing (2.48). These values are very similar, especially creating the image of a product and a company, which may mean that the population find it very important that a particular product is clearly associated with a particular company and vice versa.

Very few respondents associated the LCC analyses with the ability to improve the packaging, while none of the respondents

Table 2 Reasons for participation in the project and LCC

\begin{tabular}{|c|c|c|}
\hline \multicolumn{2}{|c|}{ Motivation for LCC } & \multirow{2}{*}{$\begin{array}{l}\text { Compliance by a } \\
\text { five-point scale } \\
\text { [as a weighted average] } \\
0 \text {-insignificant (min) } \\
\text { 5-very significant (max) } \\
3.72\end{array}$} \\
\hline 1 & New product/service development & \\
\hline 2 & Product/service improvement plans & 3.55 \\
\hline 3 & Free service & 4.24 \\
\hline 4 & $\begin{array}{l}\text { Cooperation with a well-known centre } \\
\text { (getting a certificate confirming the } \\
\text { cooperation) }\end{array}$ & 3.97 \\
\hline 5 & $\begin{array}{l}\text { Existing product/process seen as } \\
\text { adversely affecting the environment }\end{array}$ & 2.14 \\
\hline 6 & Similar measures taken by competition & 2.00 \\
\hline 7 & Shaping their image in the eyes of suppliers & 3.16 \\
\hline 8 & Shaping their image in the eyes of clients & 3.52 \\
\hline 9 & At the express request of suppliers & 1.72 \\
\hline 10 & $\begin{array}{l}\text { At the express request of clients } \\
\text { (their reported preferences) }\end{array}$ & 1.90 \\
\hline
\end{tabular}


Fig. 4 Evaluation of the usefulness of the LCC analyses, where 0 insignificant ( $\mathrm{min}$ ), 5 very significant $(\max )$

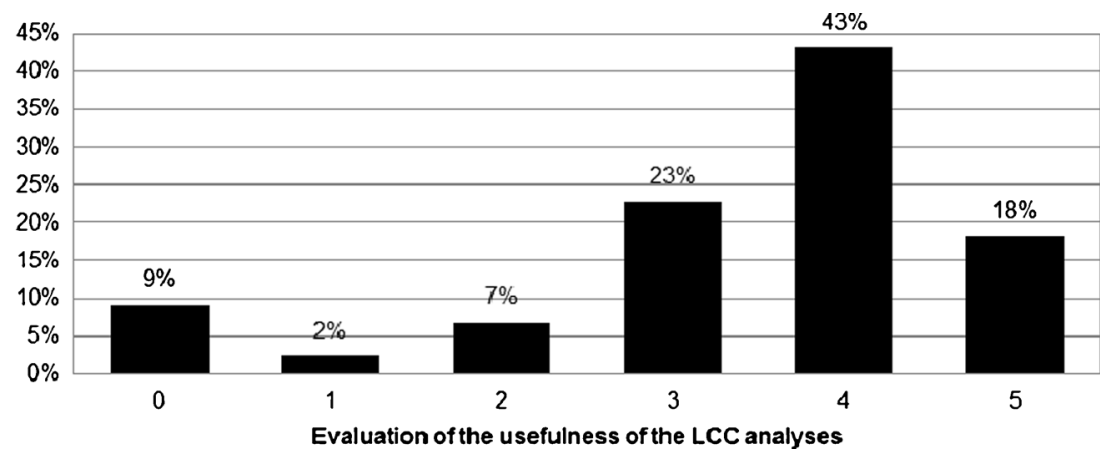

provided other opportunities for using the results of the analyses. This may indicate little creativity of the respondents in terms of product development, lack of interest in any activities supporting manufacturing processes or sales or lack of confidence in this type of analysis. Detailed data are shown in Table 3 .

The next question concerned the areas which caused most difficulties for entrepreneurs during the LCC studies. As many as $73 \%$ of respondents said they did not have any problems with this, $18 \%$ of respondents pointed to the difficulty of collecting the relevant data needed to analyse the costs, while $11 \%$ of entrepreneurs had problems with the interpretation of the report. Difficulties in obtaining data were mostly related to the type of bookkeeping (single- or double-entry bookkeeping), and the fact that many of the data needed for the LCC, regardless of the type of bookkeeping, were not recorded in any way. The results are shown graphically in Fig. 5.

Then the manner in which the LCC results affected management models or the entrepreneurs' way of thinking about their product or service development was examined. In that case, as many as $61 \%$ of respondents replied that the results of the analyses would not affect their management practises and the way of thinking about the development of products and services. This reflects the reluctance of the majority of the companies surveyed to make changes to management models adopted. However, almost $40 \%$ of respondents noted the possibility of introducing changes in this area (Fig. 6).

Table 3 Potential areas of application of LCC results according to the companies analysed

\begin{tabular}{|c|c|c|}
\hline \multicolumn{2}{|c|}{ Areas of application of LCC results } & \multirow{2}{*}{$\begin{array}{l}\text { Compliance by a } \\
\text { five-point scale } \\
\text { [as a weighted average] } \\
0 \text {-insignificant (min) } \\
\text { 5-very significant (max) } \\
2.48\end{array}$} \\
\hline 1 & Marketing & \\
\hline 2 & Product development & 3.20 \\
\hline 3 & Packaging improvement & 0.86 \\
\hline 4 & Creating the image of a product & 2.66 \\
\hline 5 & Creating the image of an organisation & 2.59 \\
\hline
\end{tabular}

Another question concerned the possibility of a company using the LCC technique in the future. The vast majority, i.e. $3 / 4$ of respondents, did not exclude the possibility of using a life cycle cost analysis in the future, and $9 \%$ of respondents said they would definitely use the solutions offered by the LCC methodology. Only $14 \%$ answered that they were not likely to use a life cycle cost analysis in the future, and just $2 \%$ of respondents reported a total lack of willingness to use the tool. These results strongly depend on the specific nature of the branch of industry in which the entrepreneurs operate. In the case of simple products or services, with a short period of use, the multi-dimensional calculation of costs using the LCC methodology can pose a lot of problems, for example, correct identification of various categories of costs, acquisition of accurate cost data and then their correct interpretation. Therefore, some companies do not intend to carry out this type of complex calculations, as they may appear to be superfluous. The LCC method is a very useful tool for more complex products or services, with long periods of use, high reliability required and high operating costs, as it may help to build long-term investment strategies (Fig. 7).

\section{Life cycle thinking in the area of cost management in the companies analysed}

If enterprises want to survive in the market, they need to abide by the principle of economic rationality, and therefore consider

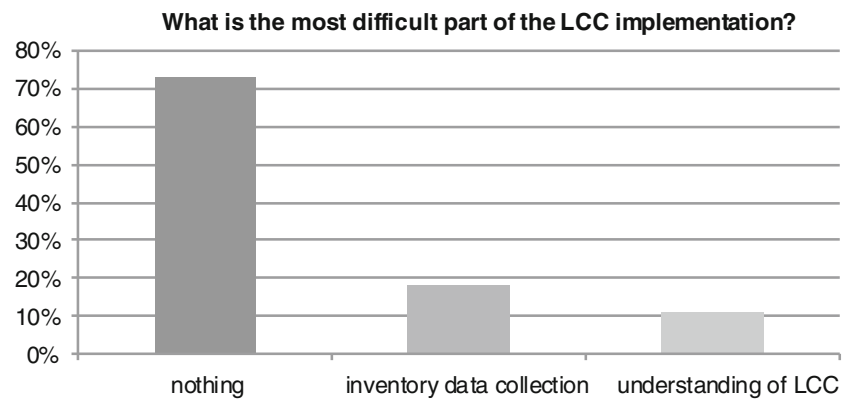

Fig. 5 Respondents' answers to the question. "What was the most difficult element in implementing the LCC?" 
Declared impact of LCC results on the change in management, business thinking and development of products and services

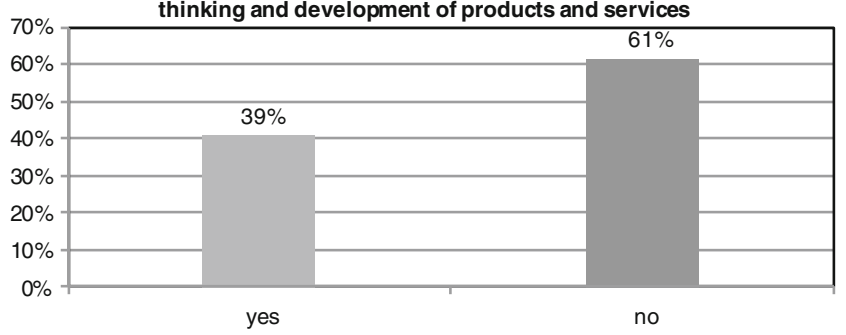

Fig. 6 Declared impact of LCC results on the change in management, business thinking and development of products/services in the companies analysed

the life cycle of their investment projects and, more specifically, the net present value generated during their implementation. Under the conditions of increased competition, it is equally important to determine the total cost of the physical life cycle of a product and use it for marketing purposes.

One of the manifestations of life-cycle thinking in the economic aspect is the estimation of costs generated outside a company, i.e. at different stages of a product life cycle. It is significant that the stages of use and end-of-life management may generate costs for both a manufacturer and a user of a product. The first two questions in the fourth part of the questionnaire focused on the use of a product, and the next three - on the product end-of-life management.

Two issues were considered in relation to the after-sales phase as follows: the cost of warranty and post-warranty service (repair, supply of spare parts) and operating costs (electricity, consumables, maintenance, etc.). Where applicable, $86 \%$ of organisations said they estimated the cost of after-sales services for a product they marketed, which is explained by the fact that warranty service is a cost driver for manufacturers and therefore it is of great interest to them. Post-warranty service, in turn, is associated with the efficiency and reliability of a product which are also important aspects of production, give increased competition. In contrast, it should be noted that only a little over $20 \%$ of the organisations analysed were particularly interested in the costs typically borne by a user of a product, and yet, these issues can also be an element of competitive advantage (Fig. 8).

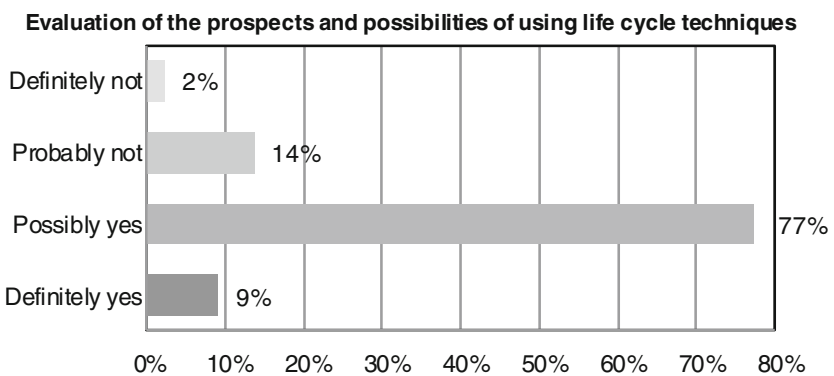

Fig. 7 Evaluation of the prospects of and opportunities for the use of life cycle techniques by the companies in the future

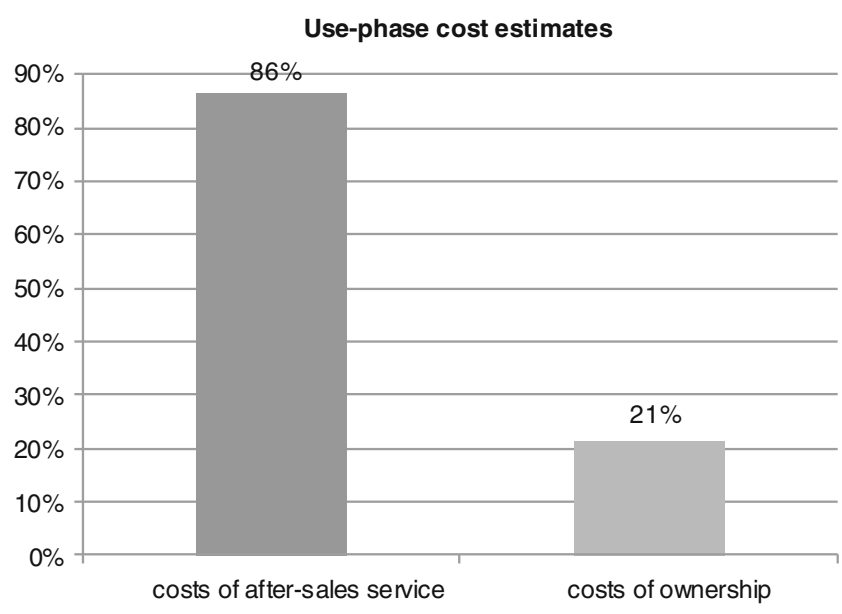

Fig. 8 Use-phase cost estimates

In the context of certain products, there are regulations (Journal of Laws of 2005, no. 180, item. 1495) that require a manufacturer to organise waste collection and recovery. Where applicable, almost $70 \%$ of the organisations responded affirmatively to the question of estimating the costs of organising waste collection and recycling in the context of new or modified products. The enterprises presented a different approach to estimating the cost of waste treatment (landfill) incurred by a user. Only $31 \%$ of the companies analysed declared such practises, and nearly $33 \%$ indicated that they estimated potential revenues from the sale of recyclable materials (Fig. 9)

The second part of the questionnaire related to the accounting of environmental costs. These costs are subject to a number of classifications, and three types were distinguished for the purposes of the survey: environmental fees, costs of waste materials and costs of environmental prevention and management. The approach to determining environmental protection costs is important as it shows an organisation's potential to integrate LCA and LCC analyses in their operation, as it is often in this context that the

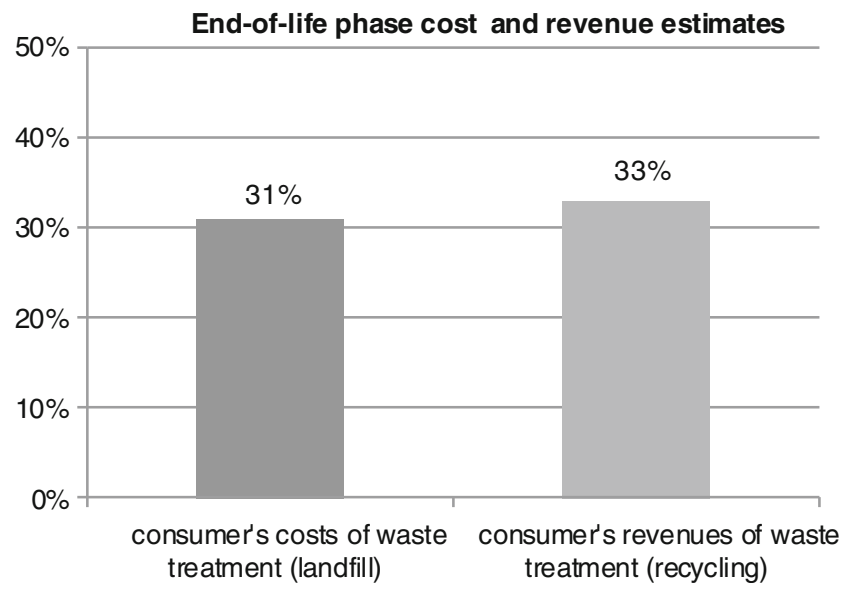

Fig. 9 End-of-life phase cost and revenue estimates 
incorporation of environmental aspects into cost calculations is considered (Shapiro 2001; Steen 2005).

A quarter of the organisations surveyed responded negatively to the question of estimating charges for the economic use of the environment, but it is worth stressing that almost every enterprise is obliged to pay such fees. As many as $60 \%$ of the companies treated them as general operating expenses, not assigning them to individual products, and almost $16 \%$ estimated them in relation to specific objects of the calculation. Another group of environmental costs included the acquisition costs of materials which were not the final products - waste products and their end-of-life management. Of the organisations surveyed, $31 \%$ showed no activity in this area, $58 \%$ considered them as part of general operating expenses and only $11 \%$ calculated them in relation to specific products. The last question concerned the costs of environmental prevention and management. A vast majority of the organisations analysed did not in general estimate those costs, $33 \%$ did, but as part of overheads, and only $4.5 \%$ accounted for them in relation to specific products (Fig. 10).

The fact that the organisations surveyed tend to treat environmental costs as general operating costs shows that the integration of LCA and LCC analyses could bring a clear synergy in terms of estimating total life-cycle costs, thus including hidden and less tangible costs.

\section{Discussion and conclusions concerning LCC-related aspects}

Analysing the results, it can be concluded that more than three quarters of the organisations do not have any formal management systems, almost $20 \%$ declared they had quality management systems and $2.2 \%$ had health and safety management systems and environmental management systems. None of the organisations had cost optimisation systems. Therefore, entrepreneurs were willing to participate in a project the aim of which was to study the life cycle costs of a product or service with an indication of potential areas for improvement of economic indicators.
The fact that participation in the project was free of charge was a very important factor for the companies. Another element was the desire to obtain a certificate confirming participation in the project and cooperation with the centre supporting entrepreneurship which is well-known in the region. Next, a relatively important argument influencing the decision to join the project included new product development plans.

The companies analysed were highly aware of the importance of carrying out economic LC analyses of products or services; however, it proved to be problematic for them to clearly define the area of their practical use, at least at the present stage of their development.

The greatest difficulties encountered by respondents were related to the acquisition of relevant data. This was mainly because of the form of accounting and the fact that not all, even the lowest costs, were monitored and divided according to the categories in which they were generated.

The results of the present study demonstrate that up to $39 \%$ of the companies recognise the potential of the cost analyses and plan to introduce measures to apply them in their business practise. The remaining $61 \%$ of respondents do not expect the results of LCC analyses to have influence on management practises and the way of thinking about the development of products and services. Obtained result should be considered in the context of usefulness of LCC analysis. Eighteen percent of companies identified the usefulness of LCC analysis as very significant, $43 \%$ as significant and $23 \%$ of the companies evaluate LCC's usefulness on the average level. It can be concluded that most of SMEs could use LCC methods in the future willingly, considering them as a useful tool.

The results obtained in the survey are strongly influenced by the particular nature of the branches of industry in which the enterprises operate, the complexity of their products and the assumed length of their life cycle. In the case of simple products, with a short life cycle, complex cost analyses may seem useless. For more complex products or services, with long periods of use, high reliability required and high operating costs, the analyses presented are useful tools that increase the economic efficiency of the projects implemented.
Fig. 10 Environmental cost estimates

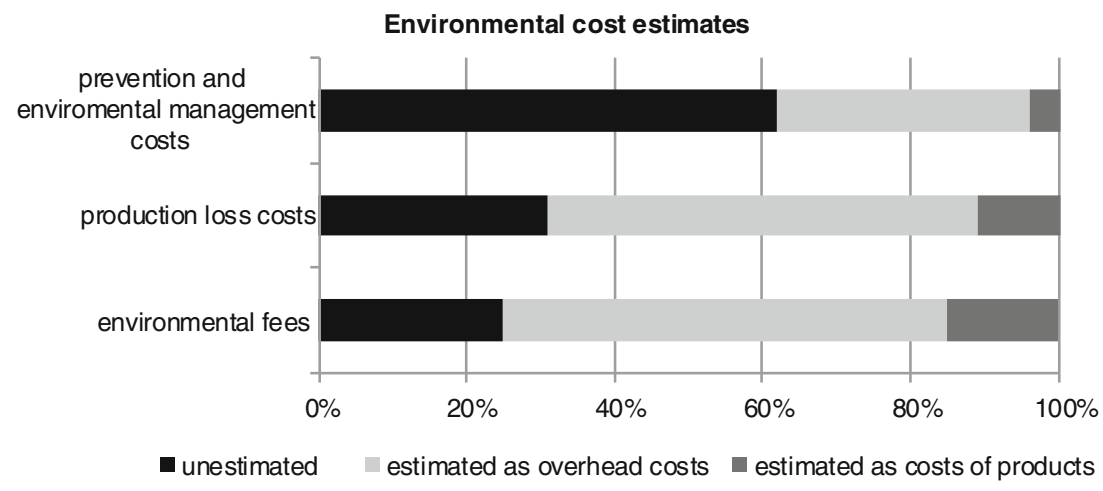


A factor directly related to effective cost management, also in relation to products or services, is warranty service fees. In this case, $86 \%$ of respondents took these costs into account in the overall balance of costs. However, costs incurred by a user, such as costs of ownership and use as well as post-warranty costs, proved to be important for only $20 \%$ of respondents.

Costs related to the organisation of waste collection and recovery, imposed by relevant legal regulations, were taken into account by nearly $70 \%$ of the organisations, but in the case of waste treatment costs (e.g. landfill) borne by users, only $31 \%$ of the enterprises, to which the regulations applied due to the specific features of their products, declared such practises, and $33 \%$ estimated possible revenues of users from the sale of recyclable materials.

The survey showed that $25 \%$ of respondents did not estimate charges for the economic use of the environment, despite the fact that each entity is required to pay such fees. Almost $60 \%$ of the companies treated them as general operating expenses, not assigning them to individual products, and almost $16 \%$ of them accounted for them in relation to specific elements in the calculation.

\section{LC techniques in Polish SMEs-final conclusions}

Life-cycle thinking has been present in Poland for several years, but so far, the application of LC techniques in Polish industry has been mainly limited to large companies, for example from the metal sector (Bieda 2012a, b). Poland seems to be a good choice for analysing the potential of LC techniques in the SME context. Firstly, this is because small- and medium-sized enterprises constitute a mainstay of the Polish economy (PAED 2008). There are about 1.7 million companies in Poland and the vast majority of them-99.8\% - belong to the category of SMEs. Compared to the EU average, the SME sector in Poland is more dominated by micro-businesses ( $95.7 \%$ of total number of enterprises) and the share of the small sector involved in the structure of companies is less than half that of the EU (Kurczewski part 1: Background and framework). A similar situation also exists in other Central Eastern European countries like Hungary and Slovenia where the share of micro-businesses is 94.8 (SBA fact sheet Hungary 2012; Bartlett and Bukvič 2001) and 92.8 \% (SBA fact sheet Slovenia 2012; Szita Tóth and Gubik 2005), respectively. Secondly, this is because Poland is currently faced with many challenges on the interface between the economy and the environment, like the transition to a low-emission economy (Bukowski and Sniegocki 2011) and the changes in the technological mix of energy production (NPRGN 2011).

Government commitments will affect the whole economy and in the end they will also reach the individual companies which will be confronted with the necessity of implementing environmental technologies. However, these changes will be introduced over 20 to 320 years, which seems to be contrary to the short-term thinking specific to SMEs. These are often companies with limited human resources (often just a few people) and financial resources (often operating on the verge of survival), with a weak position in a supply chain and, therefore, having different priorities in their daily operating. It makes the situation difficult and challenging. From the macroeconomic point of view, a huge need exists for longterm technological improvement. From the microeconomic perspective, SMEs using "here and now" thinking often limit their activity to keep their position on the market. Five key areas primarily responsible for creating the specific features of SMEs have been identified and discussed in company management and division of powers, mentality, resources, position in a supply chain and flexibility (Witczak et al. part2: LCArelated aspects). All may affect the willingness of SMEs to adopt a life cycle perspective.

The results of implementing LC techniques in Polish SMEs allow one to formulate a general conclusion that the Polish companies analysed are not currently ready to appreciate the benefits of LCT. It seems that from the point of view of SMEs, the usefulness of an LCA is seen mainly from the angle of opportunities for cost reduction (preferably in business) and increased sales (marketing). A good solution would be to conduct relatively simple, but integrated LCA/LCC analyses in SMEs so that the companies would clearly see the economic effects of the proposed environmental improvements.

The companies analysed do not seem to be ready for LCT at present, which does not mean that they will never be ready. Taking into account the ambitious assumptions of the National Programme for Development of a Low Emission Economy (NPRGN 2011), the interest in the environmental issues of SMEs, as the "main power" of the Polish economy, will have to increase and go beyond the obligatory legal regulations. It permits one to be optimistic and recognise information campaigns and educational activity as the main goals for the immediate years ahead.

Open Access This article is distributed under the terms of the Creative Commons Attribution License which permits any use, distribution, and reproduction in any medium, provided the original author(s) and the source are credited.

\section{References}

Bartlett W, Bukvič V (2001) Barriers to SME Growth in Slovenia MOST: Economic Policy in Transitional Economies 11(2):177-195

Bieda B (2012a) Life cycle inventory processes of the ArcelorMittal Poland (AMP) S.A. in Kraków, Poland basic oxygen furnace steel production. Int J Life Cycle Assess 17:463-470

Bieda B (2012b) Life cycle inventory processes of the Mittal Steel Poland (MSP) S.A. in Krakow, Poland -blast furnace pig iron productiona case study. Int J Life Cycle Assess 17:787-794 
Boyce M, Neale P (2006) Conducting in-depth interviews: a guide for designing and conducting in-depth interviews for evaluation input. Pathfinder International Tools Series; Monitoring and evaluation-2

Bukowski M, Sniegocki A (2011) Energetic mix 2050 - the scenario analysis for Poland. Report approved by Ministry of Economy. Warsaw, Poland (in Polish)

Gluch P, Baumann H (2004) The life cycle costing (LCC) approach: a conceptual discussion of its usefulness for environmental decision making. Build Environ 39:571-580

Journal of Laws of 2005 (2005) no. 180, item. 1495

Kulczycka J, Kasprzak J, Kurczewski P, Lewandowska A, Lewicki R, Witczak A, Witczak J (2011) The Polish centre for life cycle assessment - the centre for life cycle assessment in Poland. Int J Life Cycle Assess 16(5):442-444

NPRGN (2011) National Programme for Development of Low Emission Economy - the Assumptions. Approved by the Council of Ministers 16th August, 2011, Warsaw, Poland (in Polish). http://www.mg.gov. pl/files/upload/10460/NPRGN.pdf

PAED (2008) The Polish Agency for Enterprise Development. Support for pro-development and innovative projects. http://en.parp.gov.pl/ files/214/6827.pdf

PN-EN 60300-3-3 (2006) Dependability management Application guide - Life Cycle Costing PKN, Warsaw (in Polish)

SBA fact sheet Slovenia (2012) http://ec.europa.eu/enterprise/policies/sme/ facts-figures-analysis/performance-review/files/countries-sheets/ 2012/slovenia_en.pdf
SBA fact sheet Hungry (2012) http://ec.europa.eu/enterprise/policies/sme/ facts-figures-analysis/performance-review/files/countries-sheets/ 2012/hungary_en.pdf

Schischke K, Nissen NF, Sherry J, O'Rafferty S, O'Connor F, Sitek J, Pamminger R, Wimmer W (2012) Life cycle thinking in small- and medium-sized enterprises-Status quo and strategic needs in the electronics sector IN: Electronics Goes Green 2012+, Proceedings of the Joint International Conference and Exhibition September 9-12, 2012 Berlin, Germany, pp 1-6, ISBN 978-3-8396-0439-7

Schmidt WP (2003) Life cycle costing as part of design for environment, environmental business cases. Int J Life Cycle Assess 8(3):167-174

Shapiro KG (2001) Incorporating costs in LCA. Int J Life Cycle Assess 6(2):121-123

Steen B (2005) Environmental costs and benefits in life cycle costing. Manage Environ Qual 16(2):107-118

Szita Tóth K, Gubik A (2005) SMEs in the global transition IN: Managing the process of globalisation in new and upcoming EU members, Proceedings of the 6th International Conference of the Faculty of Management Koper, University of Primorska, 24-26 November 2005 Congress Centre Bernardin Portorož, Slovenia, pp. 205-214, ISBN 961-6573-03-9

TNO report (2005) Making life cycle information and interpretative tools available, TNO report B\&O-A R 2005/326 http://ec.europa.eu/ environment/ipp/pdf/study_final_clean_report.pdf 